\title{
Considerações sobre o Brasil e a geopolítica das bacias hidrográficas transfronteiriças
}

\author{
Valdir Adilson Steinke ${ }^{*}$ \\ Fabiana de Oliveira Hessel** \\ Carlos Hiroo Saito ${ }^{* * *}$
}

\section{Resumo}

Este trabalho procura, de maneira introdutória, abordar a problemática da gestão das bacias hidrográficas transfronteiriças que o Brasil compartilha com países limítrofes na América do Sul. A discussão por bacia hidrográfica serve como arcabouço para trazer a tona temas como, conservação dos recursos naturais e programas de desenvolvimento sustentável. Outro aspecto importante abordado é a questão de um compartilhamento efetivo em diferentes escalas de governos, afim de que as ações muitas vezes planejadas pelos tomadores de decisão possam de fato ser executadas. Estas abordagens permeiam conceitos como globalização, geopolítica e interdependência das nações, os quais são cruciais no encaminhamento de agendas positivas nos cenários multi ou bilaterais.

Palavras-chave: Geopolítica; Análise ambiental; Bacias Transfronteiriças.

\footnotetext{
* Prof. Adjunto Departamento de Geografia - UnB (valdirsteinke@gmail.com).

** Analista Ambiental Instituto Chico Mendes - ICMBio (fabianahessel@yahoo.com.br).

*** Prof. Associado Departamento de Ecologia - UnB (carlos.h.saito@hotmail.com).
}

Geosul, Florianópolis, v. 28, n. 56, p 89-110, jul./dez. 2013 
STEINKE, V.A et al. Considerações sobre o Brasil e a geopolítica das ...

Considerations on Brazil and Geopolitics of Transboundary River

Basins

\begin{abstract}
This is an introductory approach to the issue of the management of transboundary river basins which Brazil shares with bordering countries in the South America. The concept of river basin offers a general framework capable to analyze policies and programs focused on conservation of the natural resources and sustainable development. Another important topic is the question of an effective sharing approach in different scales of government actions, so that these actions could in fact be executed. The core concepts in discussion are globalization, geopolitics and interdependence of the nations, which are crucial in the positive agenda in the multi or bi-lateral scenes.
\end{abstract}

Key words: Geopolitics; Environmental analysis; Cross border River Basins

\title{
Introdução
}

As últimas décadas foram marcadas por mudanças consideráveis de vários paradigmas. Quando aplicadas à temporalidade humana, pode-se inferir que tais mudanças ocorreram de modo rápido em um tempo curto. Como exemplo tem-se o desenvolvimento dos meios de comunicação, principalmente, após o advento da informática e, consequentemente, da rede mundial de computadores, a qual resulta de uma rápida expansão das tecnologias que dão suporte à informática.

Tais mudanças atingiram fortemente um aspecto da sociedade moderna, a comunicação, tanto entre as pessoas, como entre os entes econômicos e políticos, ensejando o reconhecimento do paradigma da globalização. 
STEINKE, V.A et al. Considerações sobre o Brasil e a geopolítica das ...

A globalização, do ponto de vista econômico, baseia-se na descentralização do parque produtivo e no gerenciamento, em tempo real, das transações comerciais estabelecendo uma nova estrutura centro/periferia e, a partir dessa, uma nova divisão espacial e internacional do trabalho (BENKO, 1994).

Do ponto de vista da cultura, trata-se do acesso permanente a um volume de informação multicultural e em escala de tempo quase que instantânea (RAFFESTIN, 1993). O fato é que, atualmente, uma parcela significativa das pessoas pode se comunicar em tempo real independentemente de distância e localização geográfica, fato que constitui uma nova manifestação de exclusão social, já que as facilidades tecnológicas, em especial, se espacializam seletivamente, ainda não atingindo a totalidade ou sequer a maioria das comunidades. De toda forma, essa interligação entre economias e pessoas, nos planos econômico e sociocultural, ainda se confronta com os limites político-administrativos formais da figura do EstadoNação. Esse confronto acaba exacerbando contradições do ponto de vista político e recriando espaços de conflito e integração, em diferentes escalas de organização e existência social. Se considerarmos que esses limites político-administrativos constituem os fundamentos do território clássico, tido como produto de cercamento do espaço geográfico, onde se exerce o poder do Estado, segundo Cataia (2011), apoiado em Moraes (2002) e Gottmann (1952), a globalização, para alguns, poderia representar a fragilização dos fundamentos dessa concepção clássica de território.

Santos (2000) considera que a sociedade vive em um mundo confuso e, ainda, confusamente percebido, exatamente pela potencialização do progresso extraordinário das ciências e das técnicas, e pela obrigatória aceleração de tudo criado a partir desta concepção.

As novas regionalizações territoriais advindas da intensificação e consolidação da globalização induzem ao uso do território de modo diferencial, seletivo e também hierárquico. As regiões não são "tocadas" pelo processo de globalização de modo igualitário, sendo que as diferenças e desigualdades estão sendo ainda mais ressaltadas. 
STEINKE, V.A et al. Considerações sobre o Brasil e a geopolítica das ...

A globalização também expôs a fragilidade das economias nacionais, uma vez que a velocidade das possibilidades de investimentos em mercados de capitais, por exemplo, pode vir a deixar marcas avassaladoras na economia local de países emergentes que passassem pela situação de receber um aporte de recursos financeiros em investimentos em um dia e, no outro, este mesmo investimento deixar o país.

As mudanças de paradigma também trouxeram, em caráter de urgência para as discussões governamentais, assuntos tais como, integração regional ou formação de blocos econômicos capazes de superar adversidades relativas a valores étnico-culturais em busca de um fortalecimento econômico. Portanto, as adversidades são cada vez mais impulsionadas pelo fenômeno da globalização, que emerge durante a década de 1990 e se torna um desafio geopolítico mundial.

Como medida preventiva por parte dos Estados, num esforço de tentar reverter o quadro em seus aspectos perversos seria necessário que os países adotassem uma postura econômica mais sólida e com fortes bases de planejamento estratégico de longo prazo. Passa a ser fortalecido, assim, o conceito de regionalização, na qual as formações de polos econômicos são amparadas pela supranacionalidade. (VIZENTINI, 1996).

Neste contexto, há que se analisar, com mais atenção, a questão das áreas de fronteira entre países, especialmente as áreas que se compartilham, seja por identidade cultural ou questões ambientais (por exemplo, bacias hidrográficas). Assim, as regiões de fronteira, com tais características, demandam olhar para uma território que pode ser identificado como uma unidade territorial transfronteiriça, ou seja, onde os Estados possuem um limite territorial estabelecido, mas que os fluxos econômicos, culturais, sociais e principalmente ambientais não se restringem ao territórionação, constituindo assim uma zona de transição de fronteira. Essa zona de transição de fronteira poderá ter dimensões e articulações das mais variadas em função das especificidades locais e regionais.

Do ponto de vista integrador e de repercussões significativas no viés ambiental, a dinâmica de fluxos dos recursos hídricos é 
STEINKE, V.A et al. Considerações sobre o Brasil e a geopolítica das ...

sem dúvida um dos elementos essenciais ao entendimento dos processos de vizinhança entre dois ou mais Estados, pois inevitavelmente as ações desencadeadas em uma margem do rio irão repercutir direta ou indiretamente na margem oposta, é necessário, portanto, refletir com a devida antecedência a estas possibilidades de repercussões, exigindo, em primeira instância planejamento ambiental e, como escala maior a estratégia geopolítica dos respectivos Estados envolvidos.

Desta maneira, constituiu o objetivo desse trabalho, analisar aspectos geopolíticos com recorte espacial nas bacias hidrográficas transfronteiriças brasileiras e suas implicações para a gestão de recursos hídricos.

\section{Globalização, integração e meio ambiente}

Os conceitos de integração, regionalização e supranacionalidade vêm ganhando força pela ótica do meio ambiente desde que a discussão ambiental veio à tona com mais vigor e importância no cenário internacional. A eclosão no cenário internacional da temática ambiental, já dá pela conferencia de Estocolmo em 1972, no entanto, é importante frisar que naquele momento haviam elementos anteriores que balizaram tal "eclosão", tornando então tal tema em pauta internacional, assim desencadeiam-se os demais momentos pontuados na agenda internacional pela realização da II Conferência das Nações Unidas sobre Meio Ambiente e Desenvolvimento, mais conhecida como Rio-92, constituem-se nos principais marcos históricos do processo de implantação de um modelo de desenvolvimento sustentável do ponto de vista social e ambiental.

A partir de então se consolida a definição de sustentabilidade socioambiental. Como produtos da Conferência do Rio em 1992, uma série de documentos foram aprovados, os quais foram incorporados às Resoluções das Nações Unidas. Entre esses documentos figuram a Agenda 21, Convenções de Mudanças Climáticas e Diversidade Biológica, rediscutidos nos eventos 
STEINKE, V.A et al. Considerações sobre o Brasil e a geopolítica das ...

desencadeados desde então como a Rio+10 na África do Sul em 2002 e a Rio+20 realizada em 2012 no Rio de Janeiro.

De acordo com Ribeiro (2008) o tema da gestão compartilhada das águas internacionais, ou seja, aquelas que se dispersariam por mais de um país como um corpo d'água superficial ou como reserva subterrânea, é um dos temas mais debatidos nesse início de século XXI. A Convenção de Helsinque em 1992 regulamentou as estratégias de usos de recursos hídricos para os países da Europa.

Viola (2003) argumenta que a conjunção dos problemas ambientais globais, a revolução no mundo da informação, e o processo de globalização, têm sido determinantes para alteração das relações internacionais nos últimos 20 anos. Ou seja, considerando que o autor se referia ao período de 1983 a 2003, não resta dúvida que, na atualidade, acrescidos 10 anos, este processo de alteração nas relações internacionais tenha se intensificado.

De um lado a globalização representa, do ponto de vista econômico, a valorização seletiva do espaço (BECKER, 1991), promovendo conflitos e competições regionais, que resultam no aumento dos custos ambientais, com a intensificação da poluição do ar, água e solo, e do esgotamento de recursos naturais nãorenováveis e a disseminação de espécies exóticas invasoras (EHRENFELD, 2003; GOULART \& SAITO, 2012). Por outro lado, essa mesma globalização induz, contraditoriamente, a novas conformações de integração e enfrentamento conjunto. São as novas conformações de integração que constituem as aproximações multilaterais que fazem surgir discussões entre os países com a finalidade de buscar soluções de modo compartilhado, em diferentes escalas. Desta forma, vão desde as de nível mundial, como os grandes protocolos, por exemplo, o de Kyoto, que visa a diminuição da emissão de gases de efeito estufa, e no qual os países signatários assumem responsabilidades perante a sociedade global, até os mais diversos acordos multi e bilaterais que os países podem estabelecer na tentativa de resolução de problemas pontuais e específicos. 
STEINKE, V.A et al. Considerações sobre o Brasil e a geopolítica das ...

É preciso lembrar que mesmo os grandes protocolos levam a formação de blocos e a configuração de novas relações de poder, como por exemplo, o poder de mercado instituído pelos Mecanismos de Desenvolvimento Limpo - MDL e o comércio dos créditos de carbono - que reforçam o conceito de que a globalização constitui uma valorização seletiva do espaço, conforme tratado anteriormente. As discussões sobre mudanças climáticas promoveram o reconhecimento da ausência de fronteiras físicas quando se trata de emissões atmosféricas e de impactos sobre o clima, da mesma forma como a poluição ou a escassez de água levou ao reconhecimento de que as bacias hidrográficas não respeitam fronteiras político-administrativas. Essa dificuldade de conformar processos naturais em limites político-administrativos levou ao reconhecimento da necessidade de uma gestão compartilhada em toda a extensão da bacia hidrográfica.

Todos esses processos, no que tange ao aspecto geográfico, têm funcionado como uma direção, um novo rumo para o entendimento da diversidade de novas situações que dão forma e movimento aos novos recortes espaciais (SCHÄFFER, 1995).

\section{Geopolítica e bacias hidrográficas}

Historicamente, os povos tiveram forte apreço na demarcação de suas fronteiras, sem outras preocupações com o "outro lado" da fronteira, a não ser do ponto de vista das possíveis ameaças de perda de território. Neste aspecto, a questão de soberania das nações foi o mote para a falta ou mesmo a incipiente troca de informações de caráter fronteiriço, ou seja, a preocupação específica de cunho geopolítico (BENTANCOR, 1995).

Para Becker (2005) a geopolítica é marcada por pressões de todo tipo, com intervenções no contexto internacional, não se restringindo a conflitos mais intensos como as guerras, mas também por questões mais brandas, esporádicas e pontuais, as quais podem se enquadrar dentro de uma escala friccional tendo como elemento inicial e fundamental o Estado, pois este sempre fora visto enquanto 
STEINKE, V.A et al. Considerações sobre o Brasil e a geopolítica das ...

a instituição de poder e a representação oficial dos elementos políticos das nações. No entanto a atualidade exige um olhar mais profundo, pois a atuação da geopolítica se dá pela capacidade de influência nas tomadas de decisão dos Estados no que tange ao uso do território e ações estratégicas que englobam elementos externos.

A partir do aprofundamento de discussões socioambientais, sobre as quais os fóruns internacionais passam a funcionar e problemas são expostos, dá-se inicio a um processo de abertura dos debates a nível intergovernamental. Surgem assim diversas inquietações pertinentes aos aspectos culturais e sociais, na perspectiva de promover um despertar de integração possível nas regiões de fronteira.

A busca de integração multilateral requer a flexibilização de alguns paradigmas meramente geopolíticos e o entendimento de alguns aspectos físicos, visto que a imensa maioria da fronteira do território brasileiro é demarcada por cursos d'água.

A essencialidade da água para a vida é notório pelo âmbito biológico, e atualmente pelo ponto de vista social, também é indiscutível o reconhecimento que a sua essencialidade à vida não pode ser dissociada das questões culturais que determinam suas formas de utilização e das questões de delimitação de território, como ressalta Smith \& Ali (2006). Para Gleick (1994) os conflitos por recursos hídricos estão se transformando constantemente devido aos seus elementos desencadeadores, no entanto sua essência é em geral a mesma, ou seja, a necessidade por água para a vida. Tais conflitos podem ser, e em geral, são desencadeados com mais frequência de modo interno aos Estados e em outros casos por conflitos entre Estados. Aspectos como construção de represas, aumento populacional, desenvolvimento econômico, entre outros são considerados pelo autor como os disparadores de conflitos, que representam, em última análise, um exercício geopolítico em torno das águas. Numa escala de análise interna ao território brasileiro, mais especificamente delimitado ao semi-árido baiano, Pereira e Saito (2010 e 2012) identificaram essa mesma forma de uso geopolítico da posição na bacia hidrográfica pelos setores econômicos ligados à agricultura de irrigação. 
STEINKE, V.A et al. Considerações sobre o Brasil e a geopolítica das ...

Assim, é desejável que haja uma mudança de paradigma com vistas ao gerenciamento compartilhado das águas de fronteira. Isto porque os mesmos canais de drenagem que, historicamente, serviram como elementos físicos para garantir a soberania das as nações, pelo âmbito do controle territorial, inclusive militar, neste momento atual, seria extremamente importante que fossem vistos, como aglutinadores de políticas públicas dentro de uma concepção de respeito mútuo aos indivíduos. Muda-se a forma de percepção em que as fronteiras deixam de ser vistas meramente enquanto linhas divisórias representadas em um mapa, como sendo rupturas em um sistema que extrapola em muitos sentidos e aspectos a própria concepção de soberania.

Caso essa mudança de paradigma não se instaure, pode-se prever uma agudização do conflito centro-periferia pela necessidade de uns e outros de assegurarem o acesso e o domínio dos recursos naturais almejados, conforme Saito (1997). O conceito de EstadoNação pode então ressurgir na era da globalização contraditoriamente para suplantar, aparentemente, o conceito de região, de forma a atender aos interesses do capital globalizado. Os conceitos de EstadoNação, território nacional e região transfronteiriça podem ser manipulados e confrontados entre si, não de forma absoluta, mas circunstanciada, ao sabor dos interesses estratégicos do capital globalizado. O conflito entre a Argentina e o Uruguai conhecido como guerra das papeleiras é um retrato desse cenário, em que os conflitos socioambientais precisam ser analisados pela articulação entre as escalas regional e global (SAITO, 2009).

Em uma perspectiva diferenciada desses processos, pode-se dizer que em muitos casos, o conceito de região, subsidiando processos designados na literatura como "micro-regionalismos" vem ressurgir nesse cenário se referindo, desta vez, aos processos que se caracterizam pelo reconhecimento de interconexões regionais que ocorrem abaixo do nível nacional em termos de escala hierárquica (YANG, 2006).

Segundo Gleditsch et al. (2006), não se pode considerar mais que uma nação prejudique a outra em benefício próprio, utilizando 
STEINKE, V.A et al. Considerações sobre o Brasil e a geopolítica das ...

a água como instrumento de pressão ou de obtenção de vantagens econômicas, ou mesmo bélica. A localização geográfica dos territórios dos países fronteiriços ou não, à montante ou à jusante de cursos d'água, bem como, e especialmente, a extensão dos mesmos na bacia hidrográfica, constituem fatores que influenciam fortemente as tendências de conflitos entre esses países.

Assim, começa a haver uma maior percepção da necessidade de uma base cooperativa entre as nações. Nas relações internacionais, surge a teoria da interdependência, baseada na compreensão de que os países se relacionam de formas diversas, a fim de conseguir seus objetivos, e que o poder militar, por si só, não é suficiente para solucionar todos os problemas domésticos. Para os teóricos da interdependência, a cooperação seria a melhor forma das nações alcançarem seus interesses, estabelecendo "novas estruturas de relações (os regimes internacionais), onde a ação dos Estados ficaria reduzida e onde, numa visão grociana ou kantiana, a capacidade de se promoverem situações de vantagens multilaterais, eclipsando as concepções de jogos de "soma-zero", acabaria prevalecendo de forma definitiva" (VIGEVANI, 1994: 15, apud Filho, 2005). Complementarmente, Le Prestre (2000) apud Filho, (2005, p. 10) coloca que, "no referente aos problemas ambientais, que contêm efeitos transfronteiriços, os Estados não podem explorar os recursos naturais sem ter em conta seus vizinhos".

Filho (2005, p. 10), acredita ser “(...) preciso que se compreenda a bacia como uma unidade geográfica, de abrangência internacional, a fim de que se possam estabelecer políticas coordenadas de gestão e atribuir responsabilidade jurídica aos Estados ribeirinhos pelos danos causados aos demais países da bacia”.

Segundo Lanna (2004), as ações de planejamento de uso dos recursos hídricos transfronteiriços devem observar os princípios da unicidade da bacia hidrográfica, da cooperação, da utilização razoável e equitativa, da proibição de dano substancial ou sensível, do desenvolvimento sustentável e da participação pública.

A prevenção local de riscos e a sua não-transferência espacial para usuários a jusante motiva uma análise do 
STEINKE, V.A et al. Considerações sobre o Brasil e a geopolítica das ...

gerenciamento integrado a partir da hidro-solidariedade, de acordo com Mendiondo (2004, p. 10-16) essa abordagem requer:

1) Associação ética, multi-culturalidade e pluralidade de visões em torno dos recursos hídricos;

2) Estar baseada nos princípios: a) a bacia hidrográfica é a unidade físico-territorial para o planejamento e gestão hídrica sustentável, b) a gestão hídrica será descentralizada e participativa, junto ao poder público, sociedade civil, incluindo setores interessados $\mathrm{e}$ convênios e acordos pré-existentes entre as partes, c) a solidariedade não se presume, resulta da lei ou do comum acordo entre as partes, d) sempre que possível a análise em bacias embutidas (de montante a jusante) será prioritário para garantir o livre direito ao usufruto dos recursos hídricos pelos setores interessados;

3) Integração dos interesses locais, nas áreas a montante, com as necessidades das áreas a jusante; e

4) Desenvolvimento sustentável: gestão de águas e políticas de saneamento e suprimento de água potável.

Todas essas ideias que reforçam o conceito de integração direta de territórios por meio da água não são preocupações recentes, como se o fato de uma bacia hidrográfica não obedecer a uma delimitação política tenha sido "descoberto" há pouco tempo. No tocante à legislação referente à gestão dos recursos hidrográficos, o Plano Nacional de Recursos Hídricos (MMA, 2006) determina a bacia hidrográfica como unidade territorial para as ações de gestão do uso múltiplo da água. $\mathrm{O}$ conceito de bacia hidrográfica refere-se à superfície terrestre em que todas as águas fluem, através de uma sequência de ribeirões, rios e eventualmente lagos e lagoas para o mar, desembocando uma única foz, estuário ou delta. A bacia hidrográfica deverá ter em conta as suas implicações socioeconômicas, culturais e internacionais. Dentro desta região de análise deve-se determinar a utilização deste recurso natural a partir do conflito socioambiental oriundo dos diferentes usos e participações da comunidade, que é heterogênea e diversificada. 
STEINKE, V.A et al. Considerações sobre o Brasil e a geopolítica das ...

Além disso, o Brasil já teve um trecho de seus limites territoriais delimitados com base no conceito de bacia hidrográfica. De acordo com Golin (2002), um dos primeiros mapas gerados para o estabelecimento da fronteira entre o Brasil e o Uruguai, o qual se refere à Província de São Pedro do Rio Grande do Sul do Visconde de São Leopoldo, em 1841, apresentava como limites da Província os divisores de águas da bacia da Lagoa Mirim.

Muito mais que um fato pontual, tal perspectiva já vinha sendo abordada de modo amplo no plano internacional, no momento da introdução da discussão do conceito de bacia de drenagem internacional, apresentado na Finlândia em 1966 durante a 52 Conferencia Internacional Law Association, segundo Filho (2005, p. 2): “(...) uma bacia de drenagem internacional é uma área geográfica que cobre dois ou mais Estados, determinada pelos limites fixados pelos divisores de água, inclusive as águas de superfície e as subterrâneas, que desembocam num ponto final comum".

Esse conceito de bacia de drenagem internacional é mais completo e mais abrangente, englobando todo o ciclo da água. Por meio dele, não é apenas o curso de água que é território internacional, mas sim toda a bacia hidrográfica. Em 1997, a Comissão de Direito Internacional da ONU adotou o conceito de bacia de drenagem internacional, que proporciona a ideia de soberania múltipla sobre os cursos d'água transfronteiriços. A terminologia "águas internacionais" está relacionada à ideia de bacia de drenagem internacional, e vinculado a esse advêm os conceitos de rios fronteiriços ou contíguos ${ }^{1}$, rios transfronteiriços ${ }^{2}$ e lagos e reservatórios transfronteiriços ${ }^{3}$.

${ }^{1}$ Rio Fronteiriço: “curso d'água cujas margens situam-se em Estados ou Países distintos, e que formam, portanto, fronteiras terrestres." (ANA, 2006).

2 Rio Transfronteiriço: "comumente empregado como sinônimo de rio internacional ou compartilhado. Stricto sensu, tratar-se-ia de rio continuo." (ANA, 2006).

${ }^{3}$ Lagos e Reservatórios transfronteiriços: “corpos d'água que se estendem pelo território de dois ou mais Estados nacionais"; (ANA, 2006). 
STEINKE, V.A et al. Considerações sobre o Brasil e a geopolítica das ...

Existe uma diferenciação entre as situações dos rios fronteiriços e transfronteiriços, com relação às dificuldades de gestão dos recursos hídricos: nos rios transfronteiriços o passivo ambiental é maior e o planejamento insuficiente. Conforme Mendiondo e Valdés (2002), em rios transfronteiriços a situação é de extrema complexidade devido às externalidades e subsídios cruzados, o que justifica um aprofundamento em áreas-piloto e projetos de abrangência mútua, além da análise por parte da Organização das Nações Unidas sobre o estado da arte dos convênios e acordos de cooperação entre países de América Latina com relação aos recursos hídricos, segundo Querol (2003). A denominação região transfronteiriça (Cross-border Region), de acordo com Mendiondo (2004), atribui-se a formações regionais que se estendem por uma ou mais fronteiras nacionais. Constitui-se, assim, em uma forma de regionalização que neutraliza o efeito das fronteiras nacionais e faz desaparecer os limites dos Estados nacionais.

As regiões de fronteira possuem o foco no paradigma político que hoje tende a ser determinado pelo paradigma econômico. Nesse sentido, a demarcação das regiões de fronteira com recursos hídricos internacionais permeia as discussões políticas entre as nações. Essa tendência de criar comissões/empresas de gestão de recursos hídricos em zonas de fronteiras internacionais e administrá-los de forma compartilhada se confirma, em outras partes do mundo, inclusive no Brasil, como foi o caso da Hidrelétrica de Itaipu, no início da década de 1970.

\section{O Brasil e a geopolítica das bacias transfronteiriças}

A diversidade característica da região da América do Sul se reflete na importância dos recursos hídricos para a manutenção dos ambientes naturais e aqueles socialmente construídos. Segundo Mendiondo $(2000,2004)$, mais de $47 \%$ da água doce mundial e $13 \%$ do total de sedimentos que chega até os oceanos escoa por rios sul-americanos, o que representa um serviço anual ambiental de mais de U\$ 2 trilhões. Os sistemas de drenagem configuram 
STEINKE, V.A et al. Considerações sobre o Brasil e a geopolítica das ...

situações contrastantes quanto ao uso da água em regiões à jusante e à montante de um rio, de modo a criar situações de conflito entre as regiões, e até países cujas áreas estejam na bacia hidrográfica.

As características do território brasileiro colocam o país em uma situação que deve ser observada com cautela, diante das suas especificidades. Por um lado, se pode considerar o Brasil como privilegiado no contexto mundial e no sul-americano no qual, segundo Hirata (2000), o país detém 53\% da água doce do continente e uma vazão total de $177.900 \mathrm{~m}^{3} / \mathrm{s}$. Esse fato induz a existência de um "estoque" capaz de suprir o abastecimento de água por muitas décadas. Por outro lado, sob outra perspectiva, essa abundância pode ser "alvo" de pressões internacionais, as quais, em nome de uma suposta sustentabilidade mundial, podem propor ingerências sobre o território brasileiro, o que pode afetar os aspectos da soberania nacional.

É provável que este tipo de estratégia internacional encontre amparo nas contínuas ações de degradação que estão em franca expansão. Pelo motivo anteriormente citado e, principalmente, pela garantia de sustentabilidade, é preciso um controle rígido sobre a qualidade das águas em território brasileiro. Caso siga o modelo degradante atual, composto por uma combinação de fatores como o uso intenso para irrigação na agricultura, o descaso com os problemas de contaminação pelas áreas urbanas, o desmatamento acelerado, a construção de uma série de represas, entre outras ações que comprometem a qualidade das águas, o Brasil estará fornecendo subsídios a uma possível ingerência sobre os seus mananciais.

A preocupação com relação à soberania das águas brasileiras está explícita nos documentos oficiais do Brasil. O Plano Nacional de Recursos Hídricos - PNRH (MMA, 2006) aponta essa posição por parte do Ministério das Relações Exteriores, quando se discute nos fóruns internacionais o conceito de gestão dos recursos naturais sem o respeito às fronteiras. Quando nestes fóruns se apresentam defesas de que os recursos naturais devem ser tratados como "bens públicos globais", a posição oficial do Brasil é: “(...) as declarações, neste sentido, revelam uma visão preconceituosa, 
STEINKE, V.A et al. Considerações sobre o Brasil e a geopolítica das ...

que subestima a capacidade dos países em Desenvolvimento de gerenciar, de forma soberana e sustentável, os seus recursos naturais." (MMA, 2006, p. 120).

Ainda no que diz respeito aos acordos, convenções e tratados internacionais, e especificamente com relação à questão da água, o Brasil optou em não endossar as conclusões da Comissão Mundial de Barragens, de novembro de 2000, pelo entendimento de que o País possui na construção de empreendimentos hidrelétricos a sua principal fonte de energia e, assim, tornar-se signatário dessa Convenção significaria obstruir ou diminuir o ritmo de desenvolvimento econômico do País. Um dos principais argumentos apresentados na ocasião foi o arcabouço legal e institucional o qual é classificado pelo Plano Nacional de Recursos Hídricos como "extremamente avançado" no que diz respeito à gestão desses recursos. Esse mesmo documento ainda considera o Brasil um dos países lideres em relação à gestão democrática e participativa dos recursos naturais, entre esses, os recursos hídricos (MMA, 2006).

O contexto Sul-americano coloca o Brasil em duas situações distintas do ponto de vista geopolítico. No que diz respeito à bacia hidrográfica do Rio Amazonas, o território brasileiro encontra-se a jusante da bacia, enquanto que, com relação à bacia do Rio da Prata encontra-se a montante, o que pode ensejar interesses geopolíticos distintos. Nesse sentido, as atuações políticas são claramente diferenciadas, de acordo com a localização em relação às bacias hidrográficas.

A região da Bacia Amazônica é internacionalmente reconhecida como importante do ponto de vista econômico, geopolítico e estratégico. Caracterizada por ser o maior sistema fluvial do mundo, com aproximadamente $6.053 .384 \mathrm{~km}^{2}$, envolve nove países. O principal sistema do Rio Amazonas, o eixo Amazonas-Solimões-Ucayali, chega a $6.762 \mathrm{~km}$ de comprimento. Ademais, são mais de 1.000 afluentes principais que drenam a bacia desde os Andes, a Guiana e o planalto brasileiro, formando duas direções principais de escoamento: Norte-Sul / Sul-Norte e Oeste-Leste. (YAHN FILHO, 1992). 
STEINKE, V.A et al. Considerações sobre o Brasil e a geopolítica das ...

A compreensão da importância estratégica dos rios diante do acordo sobre o Tratado de Cooperação Amazônica se revela na consideração do poder de barganha dos peruanos quanto aos recursos hídricos da região amazônica, “(...) pelo fato de controlarem as cabeceiras dos principais rios formadores do Amazonas." (Montenegro, 2000 apud Filho, 2005). Esse cenário coloca o Brasil em uma situação desprivilegiada por não ter o controle das cabeceiras dos afluentes do Amazonas, de modo a se configurar como uma problemática relevante. Nesse sentido, a atuação política do país nas discussões que envolvem a bacia amazônica tem se revelado pacifista e passiva, de modo a evitar conflitos internacionais.

Já a Bacia do rio da Prata possui grande parte de seus cursos d'água principais em território brasileiro, localizados à montante da bacia hidrográfica. Assim, países como o Uruguai e Argentina estão em posição de desvantagem com relação à gestão internacional das águas, uma vez que são eles os potenciais alvos das degradações ambientais e dos projetos de infraestrutura focados na economia como, por exemplo, a construção da Hidrovia Paraguai-Paraná.

O Tratado da Bacia do Prata, de 1969, e a Declaração de Assunção, de 1971, reconheceram os princípios de cooperação, uso equitativo e razoável, proibição de dano sensível e desenvolvimento sustentável. Na prática, na medida em que as economias dos Estados ribeirinhos desenvolveram-se ao redor da Bacia, o uso de suas águas desencadeou, por um lado, conflitos regionais e, por outro, novas formas de cooperação.

A importância da Bacia do Prata provém da posição políticoeconômica central que ela ocupa na América do Sul e da riqueza de seus ecossistemas. Por outro lado, a região vem sofrendo graves problemas ambientais tais como, processos erosivos, sedimentação e contaminação da água e do solo, sendo consideradas áreas transfronteiriças críticas a Bacia do Alto Paraguai, a do Pilcomayo, do Bermejo, a região do Chaco.

A unidade da bacia hidrográfica, imposta pela legislação, muitas vezes não é observada, como no caso da construção da 
STEINKE, V.A et al. Considerações sobre o Brasil e a geopolítica das ...

Barragem de Itaipu, de modo que os países à montante desconsideram os efeitos que provocariam aos demais usuários. Como consequência da indivisibilidade de bacia, a cooperação entre os países co-ribeirinhos faz-se imprescindível para o uso sustentável de bacias transfronteiriças. A utilização razoável e equitativa, a proibição de dano substancial ou sensível, o desenvolvimento sustentável e a participação pública, aliados à unicidade da bacia hidrográfica e a cooperação, conformam os princípios gerais para a gestão de águas transfronteiriças. (SELL, 2006).

\section{Considerações finais}

A água é um recurso natural compartilhado, por isso a sua gestão, no plano internacional, deve ser submetida a um regime de soberania múltipla, adotando-se o conceito de bacia de drenagem internacional como princípio básico de planejamento. Dessa forma, o melhor aproveitamento das potencialidades da região só será possível com a cooperação. Os projetos e os usos que estejam direta ou indiretamente ligados às águas fronteiriças devem ser elaborados a partir de um compartilhamento de informações, anseios e problemas consequentes, levando-se em consideração a sistemática natural de fluxo das águas, a partir de discussões coletivas. As iniciativas unilaterais constituem atitudes individualistas que comprometem a sustentabilidade do sistema natural, de modo a contrariarem os objetivos de desenvolvimento socioambiental, aliado ao crescimento econômico, determinados internacionalmente na pauta do acontecimento ambiental. Os governos, e as sociedades civis dos países devem dialogar e construir coletivamente as metodologias e técnicas para a implantação de uma gestão das águas com uma visão sistêmica e com comprometimento para com as futuras gerações.

As bacias hidrográficas vêm sendo cada vez mais reconhecidas como unidades territoriais de gestão.

O conceito de bacia hidrográfica é determinado pela legislação brasileira como categoria de análise dos recursos hídricos, porém, não se pode deixar de levar em consideração que, 
STEINKE, V.A et al. Considerações sobre o Brasil e a geopolítica das ...

assim como para todo e qualquer recurso natural, a análise deve permear todas as escalas geográficas desde a local, regional, nacional até a global, pois os limites naturais nem sempre são sobrepostos aos limites políticos e administrativos.

\section{Referências bibliográficas}

ANA, RESOLUÇÃO No 467, DE 30 DE OUTUBRO DE 2006 Art. $2^{\circ}$. Dispõe sobre critérios técnicos a serem observados na análise dos pedidos de outorga em lagos, reservatórios e rios fronteiriços e

transfronteiriços. http:/www.ana.gov.br/AcoesAdministrativas/Resolucoes/resoluco es2006/467-2006.pdf. Acesso em: 10 de fev. de 2007.

BECKER, B. K. Amazônia brasileira: uma área crítica no contexto geopolítico mundial. In: MACIEL, T. (org.). O Ambiente Inteiro - a contribuição crítica da Universidade à questão ambiental. Rio de Janeiro: UFRJ, p. 91-121, 1991.

BECKER, B. K. Geopolítica da Amazônia. Estudos Avançados 19 (53), pp. 71-86. 2005.

BENKO, G. Organização econômica do território: algumas reflexões sobre a evolução do século XX. In: SANTOS, M.; SOUZA, M. A. de; SILVEIRA, M. L. (org.). Território: globalização e fragmentação. São Paulo: HUCITEC, p. 51-71, 1994.

BENTANCOR, G. T. Frontera e Integración. In: BENTANCOR, G. T (Org.). Práticas de Integração nas Fronteiras: temas para o Mercosul. Porto Alegre: UFRGS, 1995.

CATAIA, M.A. Território político: fundamento e fundação do Estado. Revista Sociedade \& Natureza, 23(1): 115-125, 2011. 
STEINKE, V.A et al. Considerações sobre o Brasil e a geopolítica das ...

EHRENFELD, D. Globalization: Effects on Biodiversity, Environment and Society. Conservation \& Society, 1(1), pp.99$111,2003$.

FILHO, A. G Y. O Conceito de Bacia de Drenagem Internacional no Contexto do Tratado de Cooperação Amazônica e a Questão Hídrica na Região. Revista Ambiente \& Sociedade, v. 8, n. 1, pp.1-13, jan./jun, 2005.

GLEDITSCH, N. P.; FURLONG, K.; HEGRE, H.; LACINA, B.; OWEN, T. Conflicts over shared rivers: resource scarcity or fuzzy boundaries? Political Geography, v. 25, p. 361-382, 2006.

GLEICK, P. H. Amarga Agua Dulce: los conflictos por recursos hídricos. Ecologia Politica. Barcelona. v.8, pp.85-106, 1994.

GOLIN, T. A Fronteira: Governos e Movimentos Espontâneos na Fixação dos Limites do Brasil com o Uruguai e a Argentina. Porto Alegre: L\&PM, 2002.

GOTTMANN, J. La politique des États et leur géographie. Paris: Armand Colin, 1952.

GOULART, F. F., SAITO, C. H. Modelagem dos impactos ecológicos do projeto hidroviário da Lagoa Mirim (BrasilUruguai), baseada em Raciocínio Qualitativo. Brazilian Journal of Aquatic Science and Technology, v.16(1), p.19-31, 2012.

HIRATA, R. Recursos hídricos. In: TEIXEIRA, W. ; TOLEDO, M. C. M.; FAIRCHILD, T. R. ; TAIOLI, F. (Org.). Descifrando a Terra, São Paulo: Oficina de Textos, p. 421-442, 2000.

LANNA, A. E. Aspectos sociales e institucionales en la gestión integrada del agua con un enfoque de cuenca. In: CIRELLI, A. F.; MOLINA, V. S. El agua en iberoamérica. Experiencias en gestión y valoración del agua. Buenos Aires: CYTED, p. 83-100, 2004. 
STEINKE, V.A et al. Considerações sobre o Brasil e a geopolítica das ...

MENDIONDO, E. M. Towards the Renaturalization of Riparian Areas in South America Through an Interdisciplinary Approach: Management Opportunities. In: Deutscher Tropentag. Proceedings. Berlin: ATSAF, v. 1, 2000.

MENDIONDO, E. M. Gestão Hídrica Sustentável em Bacias Sulamericanas para o século XXI - Desafios da HidroSolidariedade em Projetos Transnacionais. São Carlos: USP, 2004. Relatório Técnico do NIBH-SHS/EESC/USP.

MENDIONDO, E. M. ; VALDES, J. B. . Strategies for sustainable development of water resources systems. In: Intern. Conf. Of New Trends In Water \& Environ. Eng. For Safety \& Life: EcoCompatible Solutions For Aquatic Ecosystems, 2., 2002, Capri. New Trends in Water \& Environ. Eng. for Safety \& Life: EcoCompatible Solutions for Aquatic Ecosystems. Rotterdam: Balkema, v. 1, p. 1, 2002.

MMA - Ministério do Meio Ambiente. Plano Nacional de Recursos Hídricos. Panorama e estado dos recursos hídricos do Brasil: Volume 1/ Ministério do Meio Ambiente, Secretaria de Recursos Hídricos. - Brasília: MMA, 2006.

MMA- Ministério do Meio Ambiente Coordenação do Plano Nacional de Recursos Hídricos: Relatório da Oficina Gestão de Recursos Hídricos Transfronteiriços. 2005. Disponível em http://pnrh.cnrhsrh.gov.br/pag/documentos/sem_nac/RelatorioOficina_GestaoRHT ransfonteirico.pdf

MORAES, A.C.R. Território e história no Brasil. São Paulo: Hucitec/Annablume, 2002.

PEREIRA, M. C. N., SAITO, C. H. A geopolítica e as ilusões sobre a democracia e participação social na gestão de recursos hídricos: o Comitê de Bacia Hidrográfica do rio Paraguaçu (BA) 
STEINKE, V.A et al. Considerações sobre o Brasil e a geopolítica das ...

como estudo de caso In: V Encontro Nacional da ANPPAS, 2010, Florianópolis-SC. Anais do V Encontro Nacional da ANPPAS, GT9: Água, território, democracia e governança. FlorianópolisSC: UFSC/ANPPAS, 2010. p.1-13.

PEREIRA, M. C. N., SAITO, C.H. É possível desvirtuar a participação social na gestão dos recursos hídricos? Análise espacial aplicada ao Comitê de Bacia Hidrográfica do rio Paraguaçu (BA). Espaço e Geografia (UnB), v.15, n.1, p.21-48, 2012.QUEROL, M. Estudio sobre los convenios y acurdos de cooperación entre los países de América Latina y el Caribe, en relación con sistemas hídricos y cuerpos de agua transfronterizos. Série recursos naturales e infraestructura - n. 64. Santiago de Chile: CEPAL, 2003.

RAFFESTIN, C. Por uma geografia do poder. São Paulo: Ática, 1993.

RIBEIRO, W. C. Aqüífero Guarani: gestão compartilhada e soberania. Estudos Avançados 22 (64), pp.227-238. 2008.

SAITO, C. H. Sustentabilidade como novo paradigma do consenso: crise e resgate da utopia. Geosul (UFSC), 12(23): 18-45, 1997.

SAITO, C. H. Educação Ambiental no Brasil e a crise socioambiental mundial. Espaço em Revista, 11(2): 1-14, 2009.

SANTOS, M. Por uma outra globalização: do pensamento único à consciência universal. Rio de Janeiro: Record, 2000.

SCHÄFFER, N. O. Globalização e Fronteira. In: BENTANCOR, G. T (Org.). Práticas de Integração nas Fronteiras: temas para o Mercosul. Porto Alegre: UFRGS, 223 p., 1995.

SELL, M. S. International Water Law in the La Plata Basin: Regional Application of Principles and Procedural Rules of General International Water Law. In Verfassung Und Recht In 
STEINKE, V.A et al. Considerações sobre o Brasil e a geopolítica das ...

Übersee. Law and Politics in Africa, Asia and Latin America, p. 176-191, Hamburgo: Nomos, 2006. Disponível em: http://pnrh.cnrhsrh.gov.br/pag/documentos/sem_nac/RelatorioOficina_GestaoRHT ransfonteirico.pdf

TCA 1992 TCA - Tratado de Cooperação Amazônica. Programs and Projects of The Amazon Cooperation Treaty. Quito: TCA, 1992.

SMITH, A.; ALI, M. Understanding the impact of cultural and religous water use. Water and Environment Journal, v. 20, p. 203-209, 2006.

VIOLA, E. As complexas negociações internacionais para atenuar as mudanças climáticas. In TRIGUEIRO, A. Meio Ambiente no Século 21. Rio de Janeiro: Sextante, 367p, 2003.

VIZENTINI, P. G. F. A nova ordem global: relações internacionais do século 20. Porto Alegre: UFRGS. 95 p, 1996.

YAHN FILHO, A. G. O conceito de bacia de drenagem internacional no contexto do tratado de cooperação amazônica e a questão hídrica na região. Ambiente \& Sociedade. Campinas, v.8 n.1, p.87-100, 2005.

YANG, C. The geopolitics of cross-boundary governance in the Greater Pearl River Delta, China: a case study of the proposed Hong Kong-Zhuhai-Macao Bridge. Political Geography, v. 25, p. 817-835, 2006. 